\title{
PERFORMANCE NO TERCEIRO SETOR - UMA ABORDAGEM DE ACCOUNTABILITY: Estudo de Caso eM uma Organização Não Governamental Brasileira
}

\author{
Performance Analysis of the Third Sector - Approach to \\ Accountability: A case study in Brazilian NGO
}

Recebido em 31.10.09 / Aceito em 20.04.10

\author{
June Alisson Westarb Cruz ${ }^{1}$, Carlos Olavo Quandt ${ }^{2}$, Tomás \\ Sparano Martins ${ }^{3}$ e Wesley Vieira da Silva ${ }^{4}$
}

\section{Resumo}

A perspectiva de sobrevivência e a origem dos recursos das organizações do terceiro setor são predominantemente oriundas de doações feitas por pessoas físicas e jurídicas, que geram o alicerce econômico-financeiro para a efetiva relação da organização do terceiro setor com seu objetivo específico. Nesse contexto, o presente estudo estabelece padrões econômico-financeiros de análise desse tipo de organização, com base em relatórios contábeis e dados qualitativos. O objetivo principal desse estudo é estabelecer uma metodologia de análise de organizações do terceiro setor, com base em suas demonstrações contábeis, possibilitando a comparação entre diferentes organizações concorrentes. Os indicadores sugeridos estabelecem um quadro comparativo que tem o objetivo de possibilitar ao "doador" de recurso analisar a instituição que receberá determinados valores, com base em indicadores de seu desempenho. O estudo apresenta uma abordagem teórica do contexto geral do terceiro setor no Brasil, com uma abordagem empírica aplicada a uma organização que atua na inclusão social de crianças e adolescentes de comunidades de baixa renda por meio do esporte. Como resultado, pode-se apresentar uma análise completa da organização, possibilitando uma melhor percepção estrutural da organização perante seus stakeholders.

Palavras-chave: Desempenho; Terceiro Setor; Indicadores.

1 Doutorando em Administração Estratégica (PUCPR). Professor da PUCPR e consultor da El-Kouba Consultores Associados. E-mail: june.cruz@ymail.com

2 PhD. Professor da PUCPR. E-mail:Carlos.quandt@pucpr.br

3 Doutorando em Administração Estratégica (PUCPR). Diretor Acadêmico da Faculdade Paranaense. E-mail: tomas@philyoung.com

4 Doutor em Engenharia de Produção, Professor da PUCPR. E-mail:wesley.vieira@pucpr.br 


\begin{abstract}
The perspective of surviving and the origins of organization resources in the third sector comes from donations made by people and companies, that generate the economical and financial basis for the effective relationship between the third sector organization and its specific objective. In this context the present study establishes analytical financial-economical patters for this kind of organization, based on accounting reports and qualitative data. The main objective of this paper is to establish a methodology to analyze third sector organizations based on their accounting demonstrations, enabling the comparisons between different competitors. The indicators suggested establish a comparative framework that has the objective of enabling the resource donator analyze the institution that will receive certain values based on the performance indicators. The study presents a theoretical approach in the third sector general context in Brazil and with an empirical approach applied to an organization in the third sector that acts in the social inclusion of children and teenagers in low income communities through Sport. As a result a complete analysis of organization can be presented, enabling the Best structural perception among its stakeholders.
\end{abstract}

Keywords: Performance; Third Sector; Indicators.

\title{
1 Introdução
}

A sociedade brasileira passou por uma série de transformações, nos últimos anos, em função do processo de democratização política, das comodidades tecnológicas, do aumento da capacidade de escolha e qualidade no consumo, da estabilidade econômica, da liberação dos mercados e das privatizações (CASAROTTO; PIRES, 2001). Camargo et al. (2001) afirmam que a chamada "crise do Estado" brasileiro ou a implementação do "Estado mínimo" (CRUZ, 2006, p. 1), inviabilizou algumas funções governamentais, no intuito de prover o bem-estar social, oferecendo ao terceiro setor maior autonomia para lidar com a causa pública. Observa-se uma tendência à descentralização da responsabilidade social numa nação caracterizada pela complexidade de culturas, extensão territorial e uma série de necessidades sociais oriundas das mais diversas origens.

Com base nessa crescente demanda do terceiro setor junto à sociedade e partindo do pressuposto de que essa demanda necessita de recursos financeiros para ser suprida, percebese a existência da concorrência entre as organizações na procura de formas de financiamento para seus projetos e objetivos.

Nesse contexto, apresenta-se um estudo de caso de uma organização do terceiro setor que atua na inclusão social de crianças e adolescentes de comunidades de baixa renda por meio do esporte, em todo território nacional. Propõe-se a aplicação de métodos qualitativos e quantitativos para avaliação de organizações do terceiro setor, abordando uma metodologia oriunda da análise de demonstrações contábeis, adaptadas ao contexto específico do setor, com o objetivo de auxiliar possíveis investidores "doadores" na análise da organização recebedora de recursos financeiros.

Deve-se deixar claro o delineamento deste estudo, que aborda a análise da instituição do terceiro setor na gestão de ativos e passivos, e não a indicação da qualidade dos serviços e projetos executados, pois, nesse contexto, outros fatores devem ser também analisados.

O presente estudo apresenta a seguinte estrutura: introdução, referencial teórico, metodologia, apresentação e análise dos dados e considerações finais. 


\section{Referencial Teórico}

Devido à temática de o estudo relacionar a mensuração de desempenho em organizações do terceiros setor, o presente referencial apresenta-se estruturado nos seguintes temas: contexto geral do terceiro setor e formas de avaliação de desempenho no terceiro setor.

\subsection{Contexto geral do terceiro setor}

Salvatore (2004) define terceiro setor como organizações de natureza privada e finalidade pública, portanto, sem fins lucrativos, cujas ações estão voltadas para questões como cidadania, emancipação, autonomia e direitos da população em geral. Nesse contexto, Queiroz (2004) destaca a importância dessas organizações, afirmando que, na medida em que a sociedade reconhece a necessidade de transformação social, ela legitima o terceiro setor como veículo desse processo, acentuando a responsabilidade das organizações com qualidade da gestão e eficácia das ações e projetos sociais. Para Junqueira (2000), o terceiro setor não pode ser considerado Estado nem mercado, sendo organizações que não têm seu foco voltado à distribuição de lucros para acionistas ou diretores, e sim ao atendimento de interesses públicos. Dessa forma, o terceiro setor vem comportando uma série de organizações sociais, porém com características próprias, pois cada organização tem independência para determinar seu futuro.

As organizações não governamentais sem fins lucrativos de finalidade social, cultural, ambiental ou afim (organizações que caracterizam o terceiro setor) movimentam mais de US\$ 1 trilhão em investimentos no mundo, cerca de US\$ 10 bilhões deles no Brasil. Estimase que o número de entidades que compõem o terceiro setor seja superior a 540 mil, incluindo Organizações Não Governamentais, Associações Civis, Unidades Assistenciais e Fundações, gerando cerca de 5\% dos empregos do mundo (TACHIZAWA, 2004, p. 21). O quadro 1 apresenta o panorama das ONGs no Brasil.

\begin{tabular}{|l|c|}
\hline \multicolumn{1}{|c|}{ Principais Beneficiários } & $\%$ \\
\hline Organizações populares e movimentos sociais & 61,73 \\
\hline Crianças e adolescentes & 40,31 \\
\hline Mulheres & 39,29 \\
\hline População em geral & 29,08 \\
\hline Trabalhadores e sindicatos rurais & 25,00 \\
\hline
\end{tabular}

Quadro 1 - Panorama das ONGs no Brasil

Fonte: Tachizawa (2004).

Segundo Tachizawa (2004), seus dados são fruto da pesquisa realizada pela Associação Brasileira de Organizações Não Governamentais, e salienta que o desafio contemporâneo do setor é a falta de recursos e o aumento da demanda de trabalho. Nesse contexto, surge como alternativa a formação de parcerias e alianças estratégicas, além da reorganização institucional, entre outros.

Para Dias e Rodrigues (2002), o crescimento das organizações do terceiros setor é consequência das várias pressões sociais aliadas às mudanças tecnológicas e à contínua desconfiança da capacidade do Estado em atender as demandas sociais. Salamon (1998) destaca quatro 
crises que convergem para a limitação do papel do Estado e do aumento de ações do terceiro setor:

- Crise do bem-estar social (welfare state): refere-se a uma suposta expansão da capacidade do estado em atender ao bem-estar social até o momento em que os gastos públicos superam a arrecadação, diminuindo a capacidade de atender à população em suas necessidades e pressionando a diminuição da dependência dos indivíduos em relação ao Estado;

- Crise de desenvolvimento: sugere a reflexão do desenvolvimento por meio de novos parâmetros, envolvendo a sociedade civil, representada pelas organizações do terceiro setor, e destacando a limitação do Estado como agente de desenvolvimento;

- Crise ambiental global: o crescimento econômico em detrimento das questões sociais e ambientais estimulou iniciativas público-privadas voltadas à intermediação de políticas e ações dirigidas ao consumo sustentável de recursos naturais;

- Crise do socialismo: contribuiu para o aumento da participação do terceiro setor na busca de satisfazer necessidades sociais e econômicas, incentivando novas iniciativas cooperativas orientadas pelo mercado e pelo terceiro setor (DIAS; RODRIGUES, 2002).

Observando a Geração três, citada por Korten (1997 apud QUEIROZ, 2004), destacamse algumas evidências que denotam a mobilização e o exercício de cidadania pelo terceiro setor, sendo observado, segundo o autor, um amadurecimento das relações entre organizações privadas, públicas e a sociedade civil, como segue:

1) o trabalho do Conselho da Comunidade Solidária, que teve início em 1995 e "evoluiu com base na constatação de que a sociedade civil contemporânea se apresenta como parceira indispensável de qualquer governo no enfrentamento da pobreza, das desigualdades e da exclusão social" (CARDOSO, 1999 apud QUEIROZ, 2004, p. 43);

2) a Lei 9799/99 trata da qualificação como Organização da Sociedade Civil de Interesse Público, possibilitando a progressiva mudança das políticas públicas governamentais em políticas de parceria entre organizações públicas e da sociedade civil em todos os níveis;

3) o movimento da responsabilidade social empresarial;

4) o destaque do Brasil no balanço da iniciativa 2001, na avaliação da ONU, que mobilizou cerca de 20 milhões de voluntários.

Em relação aos objetivos e às formas de gestão e estrutura de organizações de terceiro setor, podem-se ressaltar: (1) a cooperação e a responsabilidade solidária, coletiva e compartiIhada; (2) a convivência de forma pluralista, composta de assalariados, voluntários e outros parceiros; (3) o trabalho em equipes multidisciplinares, com ambiente propício ao desenvolvimento individual profissional e emocional; (4) a observância de um suporte substantivo ao trabalho pela causa; (5) diversas fontes de recurso, oriundas das mais diferentes origens; (6) processos decisórios colegiados; (7) surgimento de lideranças empreendedoras; e (8) desenvolvimento de alianças organizacionais, entre outros fatores (RODRIGUES, 2004, p. 129).

Por meio da criação de estruturas horizontais e não hierárquicas, busca-se contribuir para o desenvolvimento de um ambiente propício à aprendizagem. No caso das redes governamentais e não-lucrativas, outras vantagens decorrentes da horizontalização nas relações recebem especial atenção. Difusões da responsabilidade, multiplicidade de fontes de recursos e captação de informações oriundas de todas as áreas da rede são consideradas fatores-chave para a manutenção dos baixos níveis de controle e para a coesão da estrutura em rede (ALTER; HAGE, 1993 apud AGRANOFF; McGUIRE, 1999 apud SOUZA, 2004). O papel da gestão - aqui compreendido como um conjunto de papéis e sistemas de interações estratégicas - é essencial, pois é o ingrediente que conecta os demais componentes e gera coesão interorganizacional. 
Entretanto, Agranoff e McGuire (1999 apud SOUZA, 2004) admitem que altos níveis de horizontalização, encontrados em redes interorganizacionais colaborativas, criam dificuldades proporcionais em termos de coordenação e controle, considerando inclusive que, em se tratando de gestão de redes entre empresas, um défice na composição de fatores de coesão, como objetivos compartilhados, amplo acesso à informação e aos recursos, entre outros, pode conduzir a um estado de colapso a estrutura.

Nesse contexto, Amat e Gomes (1995) destacam algumas características de organizações sem fins lucrativos: (1) ambiguidade de objetivos; (2) variações nas possibilidades de mensuração dos resultados; (3) repetitividade ou não-repetitividade das ações exercidas. Nesse tipo de organização, a ambiguidade de objetivos é um critério crucial para o projeto do sistema de controle da organização. Pessoas com percepções e valores diferentes ou divergentes, principalmente com relação a decisões estratégicas, podem dificultar a existência de mecanismos de controle.

Fischer (2004) destaca que a gestão no terceiro setor trata de um novo desafio para pesquisas na Administração, pois, segundo a autora, até a década de 1990, as organizações do terceiro setor puderam manter-se em padrões de uma administração pouco estruturada em função de alguns condicionantes que, no cenário atual, estão se alterando rapidamente, como descreve o quadro 2.

\begin{tabular}{|l|l|}
\hline \multicolumn{1}{|c|}{ Antigamente } & \multicolumn{1}{|c|}{ Atualmente } \\
\hline $\begin{array}{l}\text { Ambiente de baixa competitividade, } \\
\text { em que não eram exigidos resultados } \\
\text { de impacto. }\end{array}$ & $\begin{array}{l}\text { Escassez de recursos em geral, condicionando que tanto } \\
\text { os financiadores quanto a clientela e a sociedade como u m todo passem a } \\
\text { exigir que a eficiência e a efetividade do desempenho organizacional sejam } \\
\text { visíveis e comprováveis. }\end{array}$ \\
\hline $\begin{array}{l}\text { A invisibilidade do terceiro setor era } \\
\text { pouco percebida pela mídia e pelos } \\
\text { formadores de opinião. }\end{array}$ & $\begin{array}{l}\text { Em função da eficiência no atendimento de necessidades sociais, essas } \\
\text { organizações estão expostas à opinião pública e são diretamente requeridas } \\
\text { para realizar alianças e parcerias que implicam novos padrões de } \\
\text { desempenho e articulação. }\end{array}$ \\
\hline $\begin{array}{l}\text { A oferta de mão de obra abundante e o o } \\
\text { emprego do trabalho voluntário } \\
\text { permitiam um desempenho regular } \\
\text { dessas organizações, ainda que sempre } \\
\text { fragilizado pela precariedade } \\
\text { e pelo inesperado. }\end{array}$ & $\begin{array}{l}\text { Alavancadas em sua importância e na expectativa de } \\
\text { que apresentem bom desempenho, essas organizações requerem } \\
\text { trabalhadores com um perfil de competências mais exigente e passam a } \\
\text { competir com as empresas privadas na busca de profissionais, em que o } \\
\text { trabalho voluntário passa a constituir atividade específica, que apoia a } \\
\text { geração dos resultados organizacionais , mas não substitui o quadro } \\
\text { profissional. }\end{array}$ \\
\hline
\end{tabular}

Quadro 2 - Condicionantes do terceiro setor

Fonte: Adaptado de Fischer (2004).

Algumas mudanças sofridas por essas organizações são descritas por Armani (1997 apud RODRIGUES, 2004) como: (1) a ampliação da escala de trabalho, articulando o local com o regional, com o nacional e com o internacional; (2) a necessidade de saber desenvolver e tirar proveito de formas de trabalho em redes organizacionais; (3) a exigência de um elevado grau de profissionalismo e especialização, condições para uma postura mais propositiva e menos reivindicatória; e (4) a necessidade de combinar ações de resistência, denúncia e proposição política com a experimentação de alternativas e a geração de benefícios concretos para a população. 


\subsection{Formas de avaliação de desempenho no terceiro setor}

Para Dias e Rodrigues (2002), cada vez mais as organizações do terceiro setor enfrentam o desafio de apresentar seus resultados e seu desempenho para seus potenciais financiadores. Esse processo de avaliação de desempenho sugere a construção de uma boa reputação perante seus stakeholders. A boa imagem perante os stakeholders parece mostrar-se cada vez mais relevante em decorrência da crescente relação do terceiro setor perante as demandas sociais e na concorrência interna do setor em busca de financiamentos.

Algumas abordagens descrevem que a avaliação é um controle realizado após a execução de determinado projeto, possibilitando estabelecer uma série histórica sobre determinada instituição, que sugere um comportamento futuro, não interferindo diretamente no desenvolvimento de um projeto já iniciado. Sendo assim, a avaliação serve como um indicador de variação de desempenho em relação aos resultados pretendidos, podendo ser inferiores, iguais ou superiores a esses resultados (TENÓRIO, 2002). Da mesma forma, Maximiano (1995) afirma que a avaliação deve ter como objeto a crítica aos objetivos estabelecidos e aos resultados alcançados, separando os objetivos em duas abordagens: quantitativa e qualitativa. Na abordagem quantitativa, são definidos os objetivos que podem ser mensurados numericamente, enquanto os objetivos na abordagem qualitativa são de difícil mensuração.

Para Tenório (2002), as avaliações de impacto sobre o bem-estar social são mais complexas, pois fica difícil conhecer a própria demanda e a expectativa dos envolvidos. Nesse contexto, surgem as avaliações dinâmicas de desempenho, que, segundo Roche (2000), devem ser alocadas aos projetos e organizações a serem estudadas, que se tornam mais complexas na medida em que o terceiro setor, em sua maioria, trabalha com demandas que devem considerar as opiniões e anseios das pessoas e comunidades envolvidas, além da mensuração dos custos envolvidos no alcance dos objetivos.

Nesse contexto, Barney (1991) aborda algumas formas de mensuração de desempenho baseadas em recursos, são elas: medidas de sobrevivência, desempenho do ponto de vista dos múltiplos stakeholders, medidas financeiras e medidas contábeis. O autor destaca, ainda, a complexibilidade da mensuração de desempenho nas organizações, levando em conta que nenhuma medida aparentemente aborda plenamente todas as variáveis de um organização, destacando que o desempenho de uma organização se dá pela satisfação dos envolvidos em relação aos recursos inicialmente aplicados.

Esta visão é muito semelhante à visão tradicional da microeconomia que, em um mercado de economia perfeita, considera uma empresa em estado de sobrevivência quando se encontra em situação de equilíbrio. Nesta ótica, o valor obtido - considerado normal - é suficiente apenas para compensar os acionistas pelos recursos investidos. Sob outra ótica, está a extinção da empresa, quando os acionistas migram para outras possibilidades, pois a empresa está gerando um valor abaixo do normal. Numa terceira perspectiva, a prosperidade ocorre quando a empresa mantém seus ativos produtivos e é capaz de atrair mais recursos, pois está gerando um valor superior ao normal.

A seguir, algumas abordagens de desempenho organizacional descritas por Barney (1991):

1) Medida de sobrevivência: nessa abordagem, sugere-se que a própria sobrevivência da empresa seja uma medida de desempenho normal. Esta medida é simples e fácil de usar, porém não proporciona a mensuração de um desempenho considerado superior;

2) Desempenho do ponto de vista dos múltiplos stakeholders: nessa abordagem, o desempenho da organização é avaliado em relação às preferências e desejos dos stakeholders. 
Nesse caso, para mensurar um tipo de desempenho, é necessário entender o contexto geral dos stakeholders, suas expectativas, objetivos e aspirações;

3) Medidas financeiras: dentre as principais medidas financeiras reconhecidas, podem-se destacar duas: Valor presente líquido e Q de Tobin. O Valor Presente Líquido tem como foco principal o valor presente do fluxo de caixa gerado pela empresa. Trata-se de uma ferramenta que possibilita perceber quanto os futuros pagamentos somados a um custo inicial estariam valendo atualmente. Já o Q de Tobin é uma combinação entre o valor da empresa no mercado e o custo de reposição da empresa;

4) Medidas contábeis: as medidas contábeis são consideradas uma das principais formas de análise de desempenho. Suas abordagens baseiam-se nos acontecimentos passados, possibilitando o entendimento do histórico da organização. As análises contábeis baseiam-se, em geral, na análise de quocientes, que abordam diferentes realidades. Essas realidades são separadas em quatro tipos de índices e duas formas de análise: índices de liquidez, índices de endividamento, índices de atividade e índices de rentabilidade; análise vertical e análise horizontal. Trata-se de cálculos matemáticos aplicados a partir das informações apresentadas basicamente pelas duas principais demonstrações contábeis: Balanço Patrimonial e Demonstração do Resultado do Exercício.

\section{Metodologia}

A abordagem metodológica do presente estudo caracteriza-se como exploratória e descritiva com a adoção de técnicas qualitativas e quantitativas. O método para o desenvolvimento da pesquisa é o estudo de caso, que, segundo Yin (2001), objetiva explicar as ligações causais em intervenções ou situações da vida real, complexas demais para tratamento por meio de estratégias experimentais ou de levantamento de dados. Neste trabalho, são utilizadas também as pesquisas bibliográfica e documental. Os dados foram coletados por meio de informações publicadas pela organização foco do estudo em seus informativos anuais dos anos de 2004, 2005 e 2006.

Para o estudo das variáveis, foram utilizadas as seguintes técnicas de pesquisa: análise de conteúdo simples, análise de demonstrações contábeis e análises adaptadas ao contexto do terceiro setor:

A Análise de Conteúdo Simples é análise do conteúdo apresentado pela entrevista ou pelo questionário propriamente dito, não havendo nenhum tratamento específico sobre os dados coletados (RICHARDSON, 1999).

A Análise de Demonstrações Contábeis é um conjunto de métodos aplicados aos relatórios contábeis que objetivam transparecer a realidade estrutural, temporal, de liquidez, atividade, endividamento e de rentabilidade da organização (MARION, 2006).

O presente estudo apresenta a aplicação dos seguintes índices e formas de análise:

1) Índices de liquidez: dentre os índices de liquidez existentes, o presente estudo aborda os índices de liquidez corrente e de liquidez imediata.

$\mathrm{O}$ índice de liquidez corrente sugere o confronto dos ativos circulantes com os passivos circulantes, determinando, segundo Marion (2006), a capacidade de pagamento das obrigações em curto prazo, sendo expresso da seguinte forma: 
Índice de liquidez corrente $=$ Ativo Circulante / Passivo Circulante

O índice de liquidez imediata pressupõe o confronto das disponibilidades (caixa e bancos) da organização com as obrigações em curto prazo (passivo circulante), demonstrando a capacidade de pagamento das obrigações de imediato, por meio dos recursos financeiros existentes, sendo expresso da seguinte forma:

Índice de liquidez imediata $=$ Disponibilidades / Passivo Circulante

2) Análise horizontal: a análise horizontal indica a série temporal da organização em suas diversas contas, possibilitando a identificação das variações de grupos e contas, sendo expressa da seguinte forma:

Valor em 2007 / Valor em $2006=\boldsymbol{X}-1=\boldsymbol{Y} * 100=? \%$

3) Análise vertical: a análise vertical demonstra a distribuição dos recursos da organização em suas diversas contas, possibilitando mensurar as contas que apresentam maior representatividade quantitativa com relação ao total, podendo ser expressa da seguinte forma:

(Conta a ser confrontada / Total da Demonstração) * 100 = índice de participação da conta

As Análises Adaptadas ao Terceiro Setor tratam da adaptação de algumas formas de análise e índices oriundos das análises contábeis e de dados qualitativos, aplicados à análise do terceiro setor. Vale ressaltar que os indicadores devem ser analisados em seu conjunto para que apresentem uma efetiva contribuição na tomada de decisões de futuros investidores (doadores). A seguir, as análises e indicadores adaptados e utilizados:

1) Índice de doações de pessoas físicas: esse índice possibilita analisar o percentual de doações que a organização recebe de pessoas físicas, relacionando o valor de doações de pessoas físicas com o total de doações recebidas no período:

Índice de doações de pessoas físicas = Doações pessoas físicas / Total das doações

2) Índice de doações de pessoas jurídicas: esse índice possibilita analisar o percentual de doações que a organização recebe de pessoas jurídicas, relacionando o valor de doações de pessoas jurídicas com o total de doações recebidas no período:

Índice de doações de pessoas jurídicas = Doações pessoas jurídicas / Total das doações 
3) Índice de gastos administrativos: esse índice possibilita identificar o percentual da receita destinado aos gastos administrativos da organização, tais como despesas com pessoal, financeiras, entre outras;

Índice de gastos administrativos $=$ Despesas Administrativas / Receita Operacional Bruta

4) Índice de aplicação em projetos sociais: esse índice auxilia na identificação do percentual da receita destinado efetivamente aos projetos sociais da organização, sendo possível, ainda, identificar o percentual para cada tipo de projeto, possibilitando analisar a prioridade da organização em destinar recursos para seus projetos sociais:

Índice de aplicação em projetos sociais = Total de aplicação em projetos / Receita Operacional Bruta

5) Investimento unitário por projeto: esse indicador possibilita identificar qual o investimento realizado para cada pessoa atendida pelos diversos projetos da organização, auxiliando na mensuração dos gastos aplicados a determinado objetivo específico:

Investimento unitário por projeto $=$ Gasto total do projeto / Quantidade de pessoas atendidas

6) Índice de acumulação de superavit: esse índice possibilita identificar o percentual de contribuição do superavit do período ao patrimônio social:

Índice de acumulação de superavit = Superavit do exercício / Patrimônio social

\section{Apresentação e Análise de Dados}

A apresentação e a análise dos dados serão estruturadas nos seguintes itens: apresentação geral da organização do terceiro setor estudada; apresentação das demonstrações contábeis (Balanço Patrimonial e Demonstração do Resultado do Exercício) inerentes aos períodos de 2004, 2005 e 2006; aplicação e análise dos indicadores e considerações gerais.

\subsection{Apresentação geral de uma organização do terceiro setor}

A organização estudada é oriunda da parceria de organizações privadas do terceiro setor e do poder público, por meio de um projeto de iniciação ao esporte iniciado em 1997, e foi fundada em março de 2003, na cidade de Curitiba, Paraná. 
Com o objetivo de promover a inclusão social por meio do esporte, a instituição atende cerca de 4.500 crianças e adolescentes em todo o território nacional. Atualmente trabalha com cinco projetos socioesportivos e três projetos educacionais. Sua estrutura diretiva conta com um presidente, dois diretores e dez conselheiros; seu orçamento é de aproximadamente 2 milhões de reais/ano, e seu patrimônio de aproximadamente setecentos mil reais. Seus projetos apresentam as seguintes características gerais:

- Projeto A: esse projeto aborda a temática da inclusão socioesportiva por meio da prática de esportes em 25 núcleos localizados em 23 municípios do estado do Paraná. Por meio de uma parceria com uma universidade local, o núcleo principal fica localizado em Curitiba, PR, atendendo aproximadamente 350 crianças e adolescentes, e os demais núcleos funcionam em parceria com escolas públicas estaduais. O projeto atende de forma contínua a aproximadamente 3.800 crianças e adolescentes de 8 a 15 anos, com um orçamento atual aproximado de 1,6 milhões, financiados integralmente pela iniciativa privada;

- Projeto B: buscando consolidar a metodologia adotada pelo Projeto A, esse projeto aborda a inclusão socioesportiva por meio da prática de esportes em quatro núcleos localizados nos estados de São Paulo, Rio Grande do Sul e Rio Grande do Norte, em escolas e colégios municipais e estaduais. Atendendo aproximadamente 509 crianças de 8 a 14 anos por meio de um acompanhamento contínuo, o projeto conta com um orçamento anual de, aproximadamente, R\$ 82 mil, financiados integralmente por empresas privadas locais;

- Projeto C: esse projeto oferece um trabalho contínuo voltado à iniciação socioesportiva e reforço educacional de 164 crianças e adolescentes de 9 a 15 anos. Realizado de forma contínua em uma praça pública na cidade de Curitiba, PR, conta com um orçamento anual aproximado de $R \$ 42$ mil reais, financiados pela iniciativa privada em parceria com o poder público;

- Projeto D: com o objetivo principal de iniciação socioesportiva e desenvolvimento educacional na área de informática e de línguas (inglês), esse projeto atende a 140 crianças de 9 a 15 anos. Realizado de forma contínua em um colégio estadual no Rio de Janeiro, conta com um orçamento anual aproximado de 29 mil reais financiados pela iniciativa privada;

- Projeto E: classificado como um projeto educacional, tem o objetivo de promover uma melhoria na qualidade de vida de crianças e adolescentes de 9 a 15 anos. Este projeto " $\mathrm{E}$ " atende de forma contínua 1.034 crianças e adolescentes de 9 a 15 anos. Por meio de quatro núcleos, distribuídos nos estados do Paraná, Rio Grande do Sul e São Paulo, conta, atualmente, com um orçamento aproximado de $\mathrm{R} \$ 10$ mil reais, financiados pela iniciativa privada;

- Projeto F: esse projeto tem como objeto principal a produção contínua de um informativo voltado a crianças e adolescentes de 9 a 15 anos de idade e a promoção de atividades em escolas públicas. Atende aproximadamente 150 crianças, envolvendo apenas parcerias estruturais entre organizações públicas e privadas, não havendo a gestão de recursos por parte de instituição do terceiro setor;

- Projeto G: esse projeto tem como objetivo a promoção eventual da capacitação para colaboradores e voluntários internos da instituição. Atende aproximadamente 150 colaboradores por ano e conta com um orçamento de, aproximadamente, $R \$ 300,00$ anuais, financiados integralmente pela iniciativa privada. Nesse caso, toda a estrutura necessária é operacionalizada pelo poder público;

- Outros projetos: com o apoio estrutural de organizações públicas e financiamento integral de organizações privadas, são promovidos, eventualmente, eventos voltados à integração dos demais projetos (A, B, C, D, E, F e G). Conta com um orçamento anual de R\$30 mil. 
O quadro 3 apresenta as características dos projetos relacionados com a organização do terceiro setor estudada.

\begin{tabular}{|c|c|c|c|c|c|c|c|c|c|c|c|c|c|c|}
\hline \multirow[b]{2}{*}{ Projetos } & \multirow[b]{2}{*}{ Objetivo } & \multirow[b]{2}{*}{ Parcerias } & \multirow{2}{*}{\begin{tabular}{c|}
$\mathbf{N}$. de \\
Pessoas \\
Atendidas
\end{tabular}} & \multirow[b]{2}{*}{$\begin{array}{l}\text { N. de } \\
\text { Núcleos }\end{array}$} & \multirow[b]{2}{*}{$\begin{array}{c}\text { Público } \\
\text { Alvo }\end{array}$} & \multirow[b]{2}{*}{ Tipo } & \multirow[b]{2}{*}{ Gestão } & \multirow[b]{2}{*}{ Estrutura } & \multirow[b]{2}{*}{$\begin{array}{c}\text { Origem de } \\
\text { Recursos }\end{array}$} & \multicolumn{5}{|c|}{ Recursos Investidos } \\
\hline & & & & & & & & & & & 2006 & & 2005 & 2004 \\
\hline $\begin{array}{c}\text { Projeto } \\
\text { A }\end{array}$ & $\begin{array}{l}\text { Iniciação } \\
\text { Sócio- } \\
\text { Esportiva }\end{array}$ & $\begin{array}{l}\text { Organizações } \\
\text { Públicas, } \\
\text { Privadas e do } \\
\text { Terceiro Setor }\end{array}$ & 3800 & 25 & Externo & Contínuo & \begin{tabular}{|c|} 
Terceiro \\
Setor
\end{tabular} & Pública & Privado & $\mathrm{R} \$$ & $1.603 .077,89$ & $\mathrm{R} \$$ & $818.376,02$ & R\$ - \\
\hline $\begin{array}{c}\text { Projeto } \\
\text { B }\end{array}$ & $\begin{array}{l}\text { Iniciação } \\
\text { Sócio- } \\
\text { Esportiva }\end{array}$ & $\begin{array}{l}\text { Organizações } \\
\text { Públicas, } \\
\text { Privadas e do } \\
\text { Terceiro Setor }\end{array}$ & 509 & & Externo & Contínuo & $\begin{array}{c}\text { Terceiro } \\
\text { Setor }\end{array}$ & Pública & Privado & RS & $82.669,09$ & $\mathrm{R} \$$ & $65.178,62$ & RS - \\
\hline $\begin{array}{c}\text { Projeto } \\
\text { C }\end{array}$ & $\begin{array}{l}\text { Iniciação } \\
\text { Sócio- } \\
\text { Esportiva }\end{array}$ & $\begin{array}{l}\text { Organizações } \\
\text { Públicas, } \\
\text { Privadas e do } \\
\text { Terceiro Setor }\end{array}$ & 164 & & Externo & Contínuo & \begin{tabular}{|c|} 
Terceiro \\
Setor
\end{tabular} & Pública & $\begin{array}{c}\text { Público e } \\
\text { Privado }\end{array}$ & RS & $42.788,45$ & $\mathrm{R} \$$ & $35.884,58$ & RS - \\
\hline $\begin{array}{c}\text { Projeto } \\
\text { D }\end{array}$ & $\begin{array}{l}\text { Iniciação } \\
\text { Sócio- } \\
\text { Esportiva }\end{array}$ & $\begin{array}{l}\text { Organizações } \\
\text { Públicas, } \\
\text { Privadas e do } \\
\text { Terceiro Setor }\end{array}$ & 140 & & Externo & Contínuo & \begin{tabular}{|c|} 
Terceiro \\
Setor
\end{tabular} & Pública & Privado & $\mathrm{R} \$$ & $29.318,01$ & $\mathrm{R} \$$ & $29.294,04$ & RS - \\
\hline $\begin{array}{c}\text { Projeto } \\
\text { E }\end{array}$ & Educação & \begin{tabular}{|l} 
Organizações \\
Públicas, \\
Privadas e do \\
Terceiro Setor
\end{tabular} & 1034 & 4 & Externo & Contínuo & $\begin{array}{c}\text { Terceiro } \\
\text { Setor }\end{array}$ & Pública & Privado & RS & $10.562,63$ & $\mathrm{R} \$$ & - & $\mathrm{R} \$$ - \\
\hline $\begin{array}{c}\text { Projeto } \\
\text { F }\end{array}$ & Educação & \begin{tabular}{|l} 
Organizações \\
Públicas, \\
Privadas e do \\
Terceiro Setor
\end{tabular} & 150 & & Externo & Contínuo & $\begin{array}{c}\text { Terceiro } \\
\text { Setor }\end{array}$ & Pública & Privado & RS & - & $\mathrm{R} \$$ & - & $\mathrm{R} \$$ - \\
\hline $\begin{array}{c}\text { Projeto } \\
\text { G }\end{array}$ & Educação & $\begin{array}{l}\text { Organizações } \\
\text { Públicas, } \\
\text { Privadas e do } \\
\text { Terceiro Setor }\end{array}$ & 150 & & Interno & Eventual & $\begin{array}{c}\text { Terceiro } \\
\text { Setor }\end{array}$ & Pública & Privado & $\mathrm{R} \$$ & 219,66 & $\mathrm{R} \$$ & - & $\mathrm{R} \$$ - \\
\hline $\begin{array}{c}\text { Outros } \\
\text { Projetos }\end{array}$ & $\begin{array}{l}\text { Iniciação } \\
\text { Sócio- } \\
\text { Esportiva }\end{array}$ & \begin{tabular}{|l} 
Organizações \\
Públicas, \\
Privadas e do \\
Terceiro Setor
\end{tabular} & Não informaldo & & Externo & Eventual & $\begin{array}{c}\text { Terceiro } \\
\text { Setor }\end{array}$ & Pública & Privado & $\mathrm{R} \$$ & $30.000,00$ & $\mathrm{R} \$$ & $25.945,28$ & $\mathrm{R} \$$ - \\
\hline
\end{tabular}

Quadro 3 - Características gerais dos projetos

\subsection{Apresentação das demonstrações contábeis}

A percepção de desempenho baseado nas demonstrações contábeis sugere a utilização de indicadores já conhecidos por analistas contábeis-financeiros, no entanto a especificidade do terceiro setor remete à mensuração do desempenho sob algumas abordagens específicas. Nesse contexto, o presente estudo irá abordar os indicadores descritos na metodologia, com base nas informações do quadro 3, no Balanço Patrimonial e na Demonstração do Resultado do Exercício.

O Balanço Patrimonial (Quadro 4) precede o registro das contas patrimoniais da organização, sendo possível a identificação das origens e as respectivas aplicações dos recursos.

A Demonstração do Resultado do Exercício tem o objetivo de evidenciar as contas de resultado da organização, possibilitando a identificação das receitas e da aplicação dos recursos por meio da execução das despesas, apresentando um resultado final representado no terceiro setor como "superavit" ou "déficit" (Quadro 5). 


\begin{tabular}{|c|c|c|c|c|c|c|}
\hline ATIVO & \multicolumn{2}{|r|}{2006} & \multicolumn{2}{|r|}{2005} & \multicolumn{2}{|r|}{2004} \\
\hline Ativo Circulante & $\mathbf{R} \$$ & $564.301,42$ & $\mathbf{R S}$ & $\mathbf{5 2 4 . 5 8 3 , 7 5}$ & $\mathbf{R} \$$ & 136.286,91 \\
\hline Caixa & $\mathrm{R} \$$ & - & $\mathrm{R} \$$ & 2,42 & $\mathrm{R} \$$ & - \\
\hline Bancos & $\mathrm{R} \$$ & $46.270,62$ & $\mathrm{R} \$$ & $41.162,09$ & $\mathrm{R} \$$ & $35.892,96$ \\
\hline Aplicações Financeiras & $\mathrm{R} \$$ & $465.642,59$ & $\mathrm{R} \$$ & $451.816,26$ & $\mathrm{R} \$$ & $100.393,95$ \\
\hline Realizável a Curto Prazo & $\mathrm{R} \$$ & $52.388,21$ & $\mathrm{R} \$$ & $31.602,98$ & $\mathrm{R} \$$ & - \\
\hline Ativo Permanente & $\mathbf{R} \$$ & $115.541,75$ & $\mathbf{R S}$ & $91.694,33$ & $\mathbf{R} \$$ & 690,00 \\
\hline Ativo Imobilizado & $\mathrm{R} \$$ & $115.541,75$ & $\mathrm{R} \$$ & $91.694,33$ & $\mathrm{R} \$$ & 690,00 \\
\hline Custo de Aquisição & $\mathrm{R} \$$ & $141.479,29$ & $\mathrm{R} \$$ & $96.998,74$ & $\mathrm{R} \$$ & 690,00 \\
\hline (-) Depreciação Acumulada & $\mathrm{R} \$$ & $(25.937,54)$ & $\mathrm{R} \$$ & $(5.304,41)$ & $\mathrm{R} \$$ & - \\
\hline TOTAL DO ATIVO & $\mathbf{R} \$$ & $679.843,17$ & $\mathbf{R} \$$ & $616.278,08$ & $\mathbf{R} \$$ & $136.976,91$ \\
\hline PASSIVO & & 2006 & & 2005 & & 2004 \\
\hline Passivo Circulante & R\$ & $131.415,86$ & $\mathbf{R S}$ & $114.296,56$ & $\mathbf{R} \$$ & 404,80 \\
\hline Contas a Pagar & $\mathrm{R} \$$ & $15.081,63$ & $\mathrm{R} \$$ & $10.667,65$ & $\mathrm{R} \$$ & 400,80 \\
\hline Obrigações Soc. E Trabalhistas & $\mathrm{R} \$$ & $112.332,63$ & $\mathrm{R} \$$ & $102.522,77$ & $\mathrm{R} \$$ & 4,00 \\
\hline Obrigações Tributárias & $\mathrm{R} \$$ & $4.001,60$ & $\mathrm{R} \$$ & $1.106,14$ & $\mathrm{R} \$$ & - \\
\hline Patrimônio Social & R\$ & $548.427,31$ & $\mathbf{R} \mathbf{S}$ & $501.981,52$ & $\mathbf{R} \$$ & 136.572,11 \\
\hline Patrimônio Social & $\mathrm{R} \$$ & $548.427,31$ & $\mathrm{R} \$$ & $501.981,52$ & $\mathrm{R} \$$ & - \\
\hline Superávit Acumulado & $\mathrm{R} \$$ & - & $\mathrm{R} \$$ & - & $\mathrm{R} \$$ & $136.572,11$ \\
\hline TOTAL DO PASSIVO & $\mathbf{R} \$$ & 679.843,17 & $\mathbf{R} \mathbf{S}$ & $616.278,08$ & $\mathbf{R} \$$ & 136.976,91 \\
\hline
\end{tabular}

Quadro 4 - Balanço Patrimonial de 2004, 2005 e 2006

\subsection{Aplicação e análise dos indicadores}

Com base nas informações observadas por meio do quadro de análise e das demonstrações contábeis, foi possível calcular a resultante dos indicadores constantes na metodologia, conforme o quadro 6. 


\begin{tabular}{|c|c|c|c|c|c|c|}
\hline \multicolumn{7}{|c|}{ DEMONSTRAÇÃO DO RESULTADO DO EXERCÍCIO } \\
\hline & \multicolumn{2}{|c|}{2006} & \multicolumn{2}{|c|}{2005} & \multicolumn{2}{|r|}{2004} \\
\hline Receita Operacional Bruta & $\mathbf{R S}$ & $2.038 .752,82$ & $\mathbf{R S}$ & $1.504 .500,80$ & $\mathbf{R S}$ & $\mathbf{1 5 0 . 2 1 4 , 2 7}$ \\
\hline Doações & $\mathrm{R} \$$ & $1.964 .110,98$ & $\mathrm{R} \$$ & $1.474 .113,98$ & $\mathrm{R} \$$ & $149.820,32$ \\
\hline Doação Pessoa Física & $R \$$ & $24.085,00$ & $R \$$ & $6.800,00$ & $R \$$ & $134.100,00$ \\
\hline Doação Pessoa Jurídica & $R \$$ & $1.926 .246,88$ & $R \$$ & 1.467.313,98 & $R \$$ & $15.720,32$ \\
\hline Doação de Bens & $R \$$ & $13.779,10$ & $R \$$ & - & $R \$$ & - \\
\hline Outras Doações & $R \$$ & - & $R \$$ & - & $R \$$ & - \\
\hline Outras Receitas & $\mathrm{R} \$$ & $74.641,84$ & $\mathrm{R} \$$ & $30.386,82$ & $\mathrm{R} \$$ & 393,95 \\
\hline Receita de Aplicações Financeiras & $R \$$ & $74.640,52$ & $R \$$ & $30.386,82$ & $R \$$ & 393,95 \\
\hline Juros Ativos & $R \$$ & 1,32 & $R \$$ & - & $R \$$ & - \\
\hline Despesas Operacionais & $\mathbf{R S}$ & $1.980 .060,86$ & $\mathbf{R S}$ & $1.113 .222,33$ & $\mathbf{R S}$ & $13.642,16$ \\
\hline Despesas Administrativas & $\mathrm{R} \$$ & $241.912,02$ & $\mathrm{R} \$$ & $178.516,70$ & $\mathrm{R} \$$ & $13.642,16$ \\
\hline Despesas com Pessoal & $\mathrm{R} \$$ & $41.469,48$ & $\mathrm{R} \$$ & $19.537,28$ & $\mathrm{R} \$$ & - \\
\hline Despesas Gerais & $\mathrm{R} \$$ & $54.162,84$ & $\mathrm{R} \$$ & $32.660,39$ & $\mathrm{R} \$$ & $9.066,57$ \\
\hline Despesas com Prestação de Serviços & $\mathrm{R} \$$ & $143.922,75$ & $\mathrm{R} \$$ & $124.435,06$ & $\mathrm{R} \$$ & $4.056,00$ \\
\hline Despesas Financeiras & $\mathrm{R} \$$ & $2.356,95$ & $\mathrm{R} \$$ & $1.883,97$ & $\mathrm{R} \$$ & 519,59 \\
\hline Programa Sócio-Esportivo & $\mathrm{R} \$$ & $1.727 .366,55$ & $\mathrm{R} \$$ & $934.705,63$ & $\mathrm{R} \$$ & - \\
\hline Projeto "A" & $\mathrm{R} \$$ & $1.603 .077,89$ & $\mathrm{R} \$$ & $818.376,02$ & $\mathrm{R} \$$ & - \\
\hline Projeto "B" & $\mathrm{R} \$$ & $22.182,20$ & $\mathrm{R} \$$ & $25.205,71$ & $\mathrm{R} \$$ & - \\
\hline Núcleo 01 & $R \$$ & $12.683,22$ & $R \$$ & $16.981,75$ & $R \$$ & - \\
\hline Núcleo 02 & $R \$$ & $6.703,70$ & $R \$$ & 948,10 & $R \$$ & - \\
\hline Núcleo 03 & $R \$$ & 519,33 & $R \$$ & 609,35 & $R \$$ & - \\
\hline Núcleo 04 & $R \$$ & $2.275,95$ & $R \$$ & $6.666,51$ & $R \$$ & - \\
\hline Projeto "C" & $\mathrm{R} \$$ & $42.788,45$ & $\mathrm{R} \$$ & $35.884,58$ & $\mathrm{R} \$$ & - \\
\hline Projeto "D" & $\mathrm{R} \$$ & $29.318,01$ & $\mathrm{R} \$$ & $29.294,04$ & $\mathrm{R} \$$ & - \\
\hline Outros Projetos & $\mathrm{R} \$$ & $30.000,00$ & $\mathrm{R} \$$ & $25.945,28$ & $\mathrm{R} \$$ & - \\
\hline Programas Educacionais & $\mathrm{R} \$$ & $10.782,29$ & $\mathrm{R} \$$ & - & $\mathrm{R} \$$ & - \\
\hline Programa "E" & $\mathrm{R} \$$ & $10.562,63$ & $\mathrm{R} \$$ & - & $\mathrm{R} \$$ & - \\
\hline Programa "F" & $\mathrm{R} \$$ & - & $\mathrm{R} \$$ & - & $\mathrm{R} \$$ & - \\
\hline Programa "G" & $\mathrm{R} \$$ & 219,66 & $\mathrm{R} \$$ & - & $\mathrm{R} \$$ & - \\
\hline Resultado Operacional & $\mathbf{R S}$ & $58.691,96$ & RS & $391.278,47$ & $\mathbf{R} \$$ & $136.572,11$ \\
\hline Superávit / Déficit do Exercício & $\mathbf{R S}$ & $58.691,96$ & $\mathbf{R S}$ & $391.278,47$ & $\mathbf{R S}$ & $136.572,11$ \\
\hline
\end{tabular}

Quadro 5 - Demonstração do Resultado dos Exercícios de 2004, 2005 e 2006 


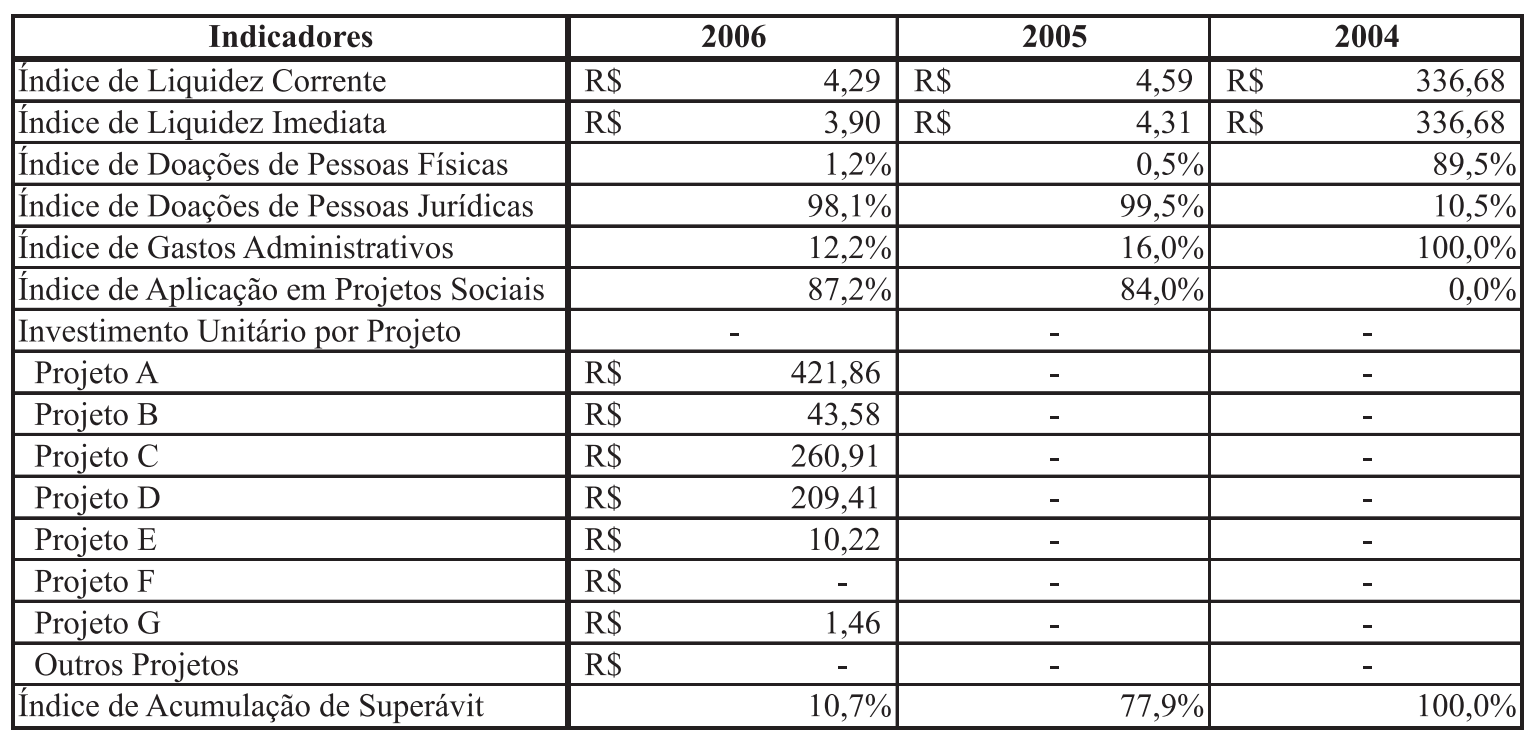

Quadro 6 - Resultado dos Índices de Análise

- Índice de Liquidez Corrente: a resultante de $\mathrm{R} \$ 4,29$ (2006) representa uma liquidez em curto prazo satisfatória, pois, para cada $\mathrm{R} \$ 1,00$ que a organização apresenta de obrigações, existem $R \$ 4,29$ de disponibilidade e de ativos permanentes para possível liquidação. Observando a série temporal, a liquidez corrente apresenta-se constante entre os períodos estudados, com uma pequena variação de aproximadamente 7\%. O período de 2004 não apresenta uma liquidez corrente passível de análise por se tratar do ano de estruturação da organização do terceiro setor;

- Índice de Liquidez Imediata: a resultante de R \$3,90 (2006) representa uma liquidez imediata bastante representativa, pois, para cada $R \$ 1,00$ de obrigações, a organização apresenta $R$ \$ 3,90 de ativos disponíveis e de rápida liquidação para possível quitação. A variação da série temporal (2005 e 2006) apresenta um percentual de decréscimo de aproximadamente $11 \%$, explicado pelo pequeno aumento do passivo circulante e do realizável a curto prazo;

- Índice de Doações de Pessoas Físicas: embora apenas 1,2\% dos recursos financeiros sejam oriundos de pessoas físicas (2006), esse indicador demonstra o envolvimento desse tipo de colaborador na obtenção de recursos e o suposto conhecimento da legislação de incentivo fiscal para pessoas físicas, que podem destinar recursos diretamente a organizações não governamentais em detrimento do recolhimento do imposto de renda aos cofres públicos. Segundo Bueno (2007), a pessoa física pode destinar até $6 \%$ do seu imposto devido a projetos culturais, desde que ela declare seu imposto de renda no formulário completo. Embora a participação seja considerada pequena, vale observar o crescimento temporal de aproximadamente 354\% de 2005 para 2006 e que a origem da organização se deu com base em recursos dessa natureza, evidenciando a importância de indivíduos na construção de ações sociais institucionalizadas;

- Índice de Doações de Pessoas Jurídicas: apresentando um percentual próximo da totalidade das origens dos recursos (98,1\% em 2006; 99,5\% em 2005), esse indicador evidencia a efetiva participação de pessoas jurídicas (públicas e privadas) na destinação de recursos voltados ao atendimento social por meio de ações geridas pelo terceiro setor voltado ao atendimento de crianças e adolescentes. Vale ressaltar que esses recursos são destinados ao terceiro setor em detrimento da destinação ao Estado (desde que a empresa esteja enquadrada no 
regime de lucro real, ela tem o limite de doação de até $1 \%$ do imposto de renda devido, conforme artigo $1^{\circ}$ do Decreto 794, de 5 de abril de 1993). Sendo assim, pode-se observar que se trata, parcialmente, de recursos financeiros de origem pública, uma vez que estes recursos deveriam ter sido recolhidos ao Estado e não o foram por um precedente legal. Outra relação possível é a percepção do aumento de aproximadamente 33\% de 2005 para 2006 nos recursos originários de pessoas jurídicas, sendo que quase a totalidade destes recursos provém de organizações privadas;

- Índice de Gastos Administrativos: a resultante de 12,2\% (2006) e de 16\% (2005) representa o percentual de recursos destinados à estrutura administrativa da organização do terceiro setor, possibilitando observar o custo da existência da organização na gestão dos projetos e recursos;

- Índice de Aplicações em Projetos Sociais: a resultante de 87,2\% (2006) e 84\% (2005) representa o percentual de recursos financeiros destinados ao objetivo principal da organização, que é promover atividades contínuas com foco socioesportivo e educacional;

- Investimento Unitário por Projeto: a resultante desse indicador objetiva mensurar o custo unitário de cada pessoa beneficiada pelo projeto com determinadas características. Tal análise apresenta grande serventia para a análise efetiva de várias abordagens. Dentre elas, pode-se destacar a importância dessa informação perante a elaboração orçamentária de novos projetos com características semelhantes ao analisado ou da análise do impacto de uma nova inserção de recurso num projeto já ativo, entre outros. Tal indicador se apresenta analisado em projetos, como segue:

- Projeto A: esse projeto apresenta um investimento unitário por pessoa beneficiada de $\mathrm{R} \$ 421,86$. Tal valor é oriundo da iniciativa privada, contando, ainda, com a estrutura física cedida pelo poder público, bem como os gastos referentes à sua manutenção e utilização. Observadas as características gerais do projeto, pode-se utilizar essa expressão monetária ( $R$ 421,86) para a mensuração de uma possível expansão do número de pessoas atendidas, na mesma capacidade instalada, ou, ainda, na mensuração e comparação da estrutura de custos per capita em diferentes projetos com características semelhantes,

- Projeto $B$ : esse projeto apresenta um investimento unitário por pessoa beneficiada de $\mathrm{R} \$ 43,58$. Da mesma forma que o Projeto $A$, os recursos financeiros do projeto são oriundos da iniciativa privada, contando ainda com a estrutura física cedida pelo poder público, bem como os gastos referentes à sua manutenção e utilização. Tal custo unitário se apresenta muito abaixo do custo do Projeto A devido às diferenças nas características de ambos, não sendo possível a comparação entre eles, devido a suas especificidades,

. Projeto C: o projeto tem um custo por pessoa atendida de $\mathrm{R} \$ 260,91$. Trata-se do único projeto gerido pela organização que recebe financiamento (em espécie) de organizações públicas e de organizações privadas. Assim como nos demais projetos, o Projeto C também funciona na estrutura física de uma organização pública,

Projeto D: o projeto tem um custo por pessoa atendida de $\mathrm{R} \$ 209,41$, com recursos oriundos integralmente da iniciativa privada. Esse projeto contou com um orçamento constante nos períodos estudados (2006 e 2007),

. Projeto E: com um custo unitário por pessoa atendida de $\mathrm{R} \$ 10,22$, o projeto atende a 1.034 pessoas em quatro diferentes núcleos, localizados em organizações públicas. Tal custo se apresenta abaixo dos demais projetos devido a suas características,

. Projeto G: trata-se de um projeto em fase operacional recente, tendo um custo unitário de $R \$ 1,46$ por pessoa atendida. Os recursos financeiros envolvidos são de $R$ \$219,66 para atender a 150 pessoas em um processo eventual de capacitação do público interno (colaboradores e voluntários); 
- Índice de Acumulação de Superavit: por meio da relação do superavit do exercício com o patrimônio social, é possível observar a contribuição da execução do exercício com o patrimônio social. Apresentou um percentual de 77,9\%, em 2006, e de 10,7\% em 2007. Sendo assim, pode-se perceber o valor da resultante da diminuição das despesas administrativas e de projetos da receita oriunda de doações financeiras de recursos públicos e privados, voltadas à integralização do resultado no patrimônio acumulado da organização gestora do terceiro setor.

\subsection{Considerações gerais}

A relação de análise de desempenho proposta sugere a relação de informações contábeis com as informações operacionais da organização gestora de recursos (organização do terceiro setor). Nesse contexto, vale perceber e destacar a importância da análise estrutural da empresa e de seus projetos, evidenciando algumas informações que podem sugerir uma melhor gestão dos recursos públicos e privados, como também a possibilidade de comparação com outras organizações e projetos com características semelhantes.

A estrutura de liquidez da organização sugere um bom panorama, possibilitando a continuidade dos seus trabalhos com segurança. Com relação à aplicação dos recursos aos projetos, pode-se afirmar um relevante repasse dos valores diretamente aos projetos, o que sugere uma estrutura de custos administrativos pouco relevante (aproximadamente $12 \%$ ) com relação ao total dos recursos aplicados nos projetos (aproximadamente 87\%), sendo complementado por uma tendência de não acumulação de patrimônio (10,7\% em 2007).

A representação da contribuição do superavit do exercício para o patrimônio social sugere uma tendência de diminuição da contribuição do resultado no patrimônio, o que ocorreu de forma bastante relevante no ano de 2006 (77,9\%). Tal fato se justifica pelo recente estabelecimento da instituição junto aos seus projetos, sendo necessária a criação de uma estrutura administrativa (patrimônio).

Por fim, vale ressaltar a estrutura de custo unitário de cada um dos projetos geridos pela organização, em que cada projeto aborda temáticas semelhantes com métodos e estruturas diferentes. É importante a relação de parceria entre organizações públicas, privadas e do terceiro setor. Vale lembrar que os custos unitários mensurados sugerem a relação de valores geridos pela organização do terceiro setor, não sendo possível a identificação dos custos oriundos das estruturas físicas cedidas por instituições públicas para o funcionamento dos projetos.

\section{Considerações Finais}

As organizações do terceiro setor vêm assumindo, cada vez mais, um papel relevante na sociedade, surgindo, assim, uma concorrência na captação de novos recursos para aplicação em projetos direcionados a realidades específicas. Nesse contexto, percebe-se a importância da correta prestação de contas por parte das organizações de terceiro setor, que utilizam suas informações e relatórios contábeis como principal fator de transparência da gestão dos recursos.

O presente estudo propôs analisar o terceiro setor sob a ótica da contabilidade, observando a relação econômico-financeira dos envolvidos. Ao compreender melhor esse contexto, pode-se enfatizar a constante relação do terceiro setor com o poder público e com a iniciativa privada, na busca de estabelecer ações sustentáveis voltadas a situações emergentes. Fica evi- 
dente o papel do terceiro setor como agente operacional que gere os recursos propostos pelos doadores (organizações públicas e privadas).

Com base no "papel operacional" desse tipo de organização, atenta-se para a estrutura patrimonial e de resultados da própria organização, sugerindo que se observem não apenas os indicadores de desempenho dos projetos isoladamente, como é comum observar, mas também uma análise interorganização.

Por fim, vale destacar que os quadros de análises apresentados devem ser observados como uma forma complementar de análise de desempenho, auxiliando na real percepção da melhor opção de "investimento" social e na percepção de sustentabilidade da instituição gestora dos recursos públicos e privados.

\section{Referências Bibliográficas}

AMAT, J. M.; GOMES, J. S. Controle de gestão: uma perspectiva global. In: CONGRESSO INTERNACIONAL DE CUSTOS - UNICAP, 4., Campinas-SP, out. 1995. Disponível em: <http://libdigi.unicamp.br/ document/?view=35> Acesso em: 14 dez. 2009.

BARNEY, J. Firm resources and sustained competitive advantage. Journal of Management, 1991.

BUENO, M. A. M. G. Incentivos fiscais no terceiro setor: uma análise das leis brasileiras e da lei 501 (C) 3, norte-americano. 2007. Monografia (Especialização em Escola de Negócios)-Fundação Getúlio Vargas, São Paulo, 2007.

CASAROTTO, N. F.; PIRES, L. H. Redes de pequenas e médias empresas e desenvolvimento local: estratégias para a conquista da competitividade global com base na experiência italiana. São Paulo: Atlas, 2001.

CAMARGO, M. C. et al. Gestão do terceiro setor no Brasil. São Paulo: Futura, 2001.

CRUZ, J. A. W. A união faz a força: a cooperação como estratégia de sobrevivência organizacional. Curitiba: Protexto, 2006.

DIAS, C. M.; RODRIGUES, R. Avaliação de impacto no as organizações do terceiro setor: uma abordagem baseada na teoria dos stakeholders. In: ENCONTRO NACIONAL DE ESTUDOS ORGANIZACIONAIS, 2002, Recife. Anais... Recife: ANPAD, 2002.
FISCHER, R. M. Gestão de pessoas nas organizações do terceiro setor. In: VOLTOLINI, R. Terceiro setor: planejamento e gestão. São Paulo: Senac, 2004.

JUNQUEIRA, L. A. P. Organizações sem fins lucrativos e redes sociais na gestão das políticas sociais. Cadernos de Administração, n. 3. São Paulo: PUC, 2000.

MARION, J. C. Contabilidade empresarial. 4. ed. São Paulo: Atlas, 1989.

MARION, J. C. Análise das demonstrações contábeis: contabilidade empresarial. São Paulo: Atlas, 2006.

MAXIMIANO, A. C. A. Introdução a Administração. São Paulo: Atlas, 1995.

QUEIROZ, M. O planejamento estratégico e as organizações do terceiro setor. In: VOLTOLINI, R. Terceiro setor: planejamento e gestão. São Paulo: Senac, 2004. p. 113-135.

RICHARDSON, R. J. Pesquisa social. São Paulo: Atlas, 1999.

ROCHE, C. Avaliação de impacto dos trabalhos de ONGs: aprendendo a valorizar as mudanças. São Paulo: Cortez, 2000.

RODRIGUES, A. L. Configurações Organizacionais em organizações sem fins lucrativos: reflexões para além da simples adoção de modelos. In: VOLTOLINI, R. Terceiro setor: planejamento e gestão. São Paulo: Senac, 2004. p. 73-97. 
SALAMON, L. A Emergência do terceiro setor: uma revolução associativa global. Revista de Administração, v. 33, n. 11, 1998. p. 83-102.

SALVATORE, V. A Racionalidade do terceiro setor. In: VOLTOLINI, R. Terceiro setor: planejamento e gestão. São Paulo: Senac, 2004. p. 23-45.

SOUZA, Q. R. Governo de redes interorganizacionais no terceiro setor: níveis de controle formal em atividades operacionais de gestão do conhecimento - o caso do COEP Paraná 2000-2003. Dissertação (Mestrado em Administração Estratégica)-Pontifícia Universidade Católica do Paraná, Curitiba, 2004.

TACHIZAWA, T. Organizações não governamentais e terceiro setor: criação de ONGs e estratégias de atuação. São Paulo: Atlas, 2004.

TENÓRIO, F. (Org.). Gestão de ONGs: principais funções gerenciais. São Paulo: FGV, 2002.

YIN, R. K. Estudo de caso: planejametno e métodos. Porto Alegre: Bookman, 2001. 